\title{
IMPACT OF IMMIGRATION ON HIV AND TUBERCULOSIS EPIDEMIOLOGY IN THE EURO-MEDITERRANEAN AREA
}

\author{
R El Aouad (rajaeelaouad@yahoo.fr) ${ }^{1}$, M Diez $^{2}$, I Cherkaoui ${ }^{1}$ \\ 1. National Institute of Hygiene, Ministry of Health, Morocco \\ 2. Secretariat of the National Plan on AIDS, Directorate of Public Health and Border Health / National Epidemiology Centre, \\ Instituto de Salud Carlos III, Spain
}

The Institut National d'Hygiène (Morocco) coordinates a consortium with the Instituto de Salud Carlos III (Spain) which is part of a project called "Impact of migration on HIV and TB epidemiology in the Mediterranean area", funded by the Sixth Framework Programme for Research of the European Commission. The project was launched in May 2007 and is intended as a specific support action to improve the capacity of the countries in the Euro-Mediterranean area for obtaining quality epidemiological information on human immunodeficiency virus (HIV) and tuberculosis (TB) among migrants, while taking into consideration ethical and legal issues related to health in migrant populations. To this end, the project proposed to hold two workshops [1] to bring together all the relevant stakeholders: delegates of international and national non-governmental organisations (NGOs) concerned with the process, experts and health professionals, researchers, representatives of the United Nations Agencies and other decision makers (Ministries of Health, Interior and Justice).

Some 30 participants from Morocco, 11 participants from Spain and 17 other international participants attended the first workshop held in Rabat (Morocco) on 5-7 November 2007. It was organised around four main topics:

1) Demographical data on immigrant populations;

2) Epidemiological data and risk data analysis of HIV and tuberculosis in overall populations;

3)Epidemiological data and risk data analysis of HIV and tuberculosis in migrant populations;

4) HIV and Tuberculosis laboratory strategy and capacity.

A summary of the discussions on those topics during the Rabat meeting are provided below.

\section{Definitions of immigration}

Delphine Antoine (Institut de Veille Sanitaire, France) proposed some definitions of the "migrant" and the "international migrant" as recommended by the United Nations (UN) [2] considering several indicators such as the country of origin, the migration pattern and the living conditions. However, she underlined the difficulty to use such definitions in TB surveillance systems as seen from experiences in France, England and other parts of Europe.

\section{Demographic data}

Monserrat Lopez Cobo (Permanent Observatory of Immigration, Ministry of Labour and Social Affaires, Spain) presented the socio- demographic characteristics of foreigners registered in the local municipalities in Spain. These may be legal migrants or not as the only requirement for registration is to provide a document proving the identity and proof of residence in the municipality in question. She underlined the increase in the numbers of registered foreigners from 542,314 in 1996 to $4,482,568$ by the end of 2006 a figure referring to both the legal migrant population as well as parts of the illegal migrant population.

Aziz Jilali Sghir (Directorate of Migration, Ministry of the Interior, Morocco) underlined the important decrease in the number of migrants without documents arrested in Morocco since 2005 as a consequence of the strategy set up by the Ministry of the Interior on the institutional and legislative level.

\section{Epidemiologic data in general population} HIV/AIDS

Mercedes Diez (Secretariat of the National Plan on Acquired Immune Deficiency Syndrome (AIDS), Ministry of Health, Spain), Aziza Bennani (Directorate of Epidemiology and Diseases Control, Ministry of Health, Morocco) and further speakers gave an overview of the HIV epidemic in their countries and presented the most important statistical data: The incidence of AIDS in Spain (35 per million in 2006) is among the highest in Europe. Between 120,000 and 150,000 persons in Spain [3] and 20,000 in Morocco [4] are estimated to be living with HIV/AIDS. The sex ratio shows an excess of males for most of the countries. The main transmission mode in Spain at the beginning of the epidemic was intravenous drug use (IDU), but is currently sexual contact, both heterosexual and homosexual. Heterosexual transmission is the principal route in the southern Mediterranean countries.

Speakers from Spain, Morocco and Mauritania presented results of HIV sentinel surveillance which showed high HIV prevalence among IDU in Spain [5-8] and among sex workers in Morocco in particular in the southern region of Agadir [9].

\section{Tuberculosis}

Speakers from Spain (Elena Rodriguez, Institute Carlos III, Ministry of Health, Spain) and Morocco (Naima Bencheikh, Directorate of Epidemiology and Diseases Control, Ministry of Health) gave detailed presentations of the epidemiological situation concerning tuberculosis: the incidence rate in 2006 was higher in Morocco compared to Spain (85 per 100,000 population versus 18 per 100,000 respectively) but both countries showed regional 
differences. In Spain, multidrug-resistant (MDR) TB is more prevalent in foreigners compared to Spaniards (6.9\% versus $2.4 \%$ respectively in strains sent to the National Reference Laboratory (NRL) in 2006) whereas the proportion of MDR TB in Morocco is $0.6 \%$ according to results of a 2004 national study.

Speakers from other Maghrebian countries presented the specific profiles of the situation in their respective countries. As in Tunisia the incidence declined from 48.6 in 1975 to 21 per 100,000 in 2006 , the country was considered to fulfil the objectives stated by the WHO to control TB. Lo Baidi (National Public Health Research Institute, Ministry of Health, Mauritania) underlined that his country has the highest TB rate in the Maghrebian region (estimated TB prevalence rate 240 per 100,000 population). Helmi Mardassi (Pasteur Institute, Tunisia) presented the results of studies on drug resistance and genetic diversity of $\mathrm{M}$. tuberculosis in Tunisia.

\section{Prisoners}

Mercedes Diez (Secretariat of the National Plan on AIDS, Ministry of Health, Spain) presented data on prisoners in Spain. Foreign inmates represent some $30.5 \%$ of the prison population. Jawad Amar (Prison Health Department, Ministry of Justice, Morocco) presented some epidemiological features of the penitentiary population in Morocco: the HIV prevalence rate is 10 times higher in prisoners and the rate of notified cases of TB in prisoners (580 cases per 100, 000 inmates) is also higher compared to the general population.

\section{Epidemiologic data in migrant population HIV/AIDS}

Mercedes Diez (Secretariat of the National Plan on AIDS, Ministry of Health, Spain) showed that the percentage of foreigners in newly diagnosed AIDS/HIV cases has clearly increased in the last years, although the rise in total numbers is not marked. Hence although there has been a sharp increase in the proportion of foreigners in newly diagnosed AIDS/HIV cases the overall increase in absolute numbers is not significant. This fact is a reflection of the relevant increase of the foreign population in Spain.

In Spain, foreigners with HIV/AIDS are, as a rule, younger than Spaniards and regarding HIV they reflect the epidemiological pattern of the country of origin. Alex Carballo-Diéguez (Columbia university, HIV Centre for Clinical and Behavioural Studies, New York State Psychiatric Institute, USA) [10] underlined that the overall HIV incidence for Hispanics in the US is four times greater than in Caucasians because of high risk factors such as men having sex with men, the incidence of IDU in this community and the "air bridge" between the Caribbean and the continental US. Claudia Natali (Instituto Superiore de Sanita) showed that in Italy, foreigners accounted for $21.7 \%$ of the total AIDS cases in 2006.

\section{Tuberculosis}

Elena Rodriguez (Institute Carlos III, Ministry of Health, Spain) underlined that of the TB cases reported in Spain in 2006, 19\% of the cases were in migrants. She also highlighted differences with the Spanish population: foreigners with TB are younger than Spaniards and the rate of MDR was higher (6.9\% versus $2.4 \%$ respectively in strains sent to the NRL in 2006). In Italy, foreigners accounted for $43.7 \%$ of the total TB cases in 2005 .

\section{Sociocultural aspects in migrant population}

Using the results of a European survey on undocumented migrants' access to healthcare carried out by the organisation Doctors of the World ("Medicos del Mundo", in Spain, or Medecins du Monde, in the French speaking world) and the Doctors of the World European Observatory in several European countries, Ramon Esteso (Medicos del Mundo) argued that carrying out field studies will help to set up new public health programmes. Miriam Navarro (Infectious Diseases Department, Hospital Al Ramon y Cajal, Madrid, Spain) presented the results of "Knowledge, Attitudes and Practices (KAP) Survey" carried out by her unit during 2006 and 2007 on sub-Saharan people from the sub-Saharan region living in Madrid, Spain. All the speakers concluded by recommending that prevention strategies should target risk factors across multiple levels (individual, community and structural factors).

\section{Access to heathcare for migrant populations}

The organisations involved in the region were represented in the workshop: the Spanish Red Cross, Medicos del Mundo (MDM), the foundation International Medical Center for Foreign Migrants (CIMME) in Spain; (Organisation Panafricaine de Lutte contre le Sida (OPALS), Association Marocaine de Lutte Contre le Sida (ALCS), Médecins sans Frontières (MSF), and Caritas in Morocco.

\section{HIV and Tuberculosis laboratory strategy and capacity}

The speakers from three laboratories (HIV National Reference Centre, National Reference TB Laboratory and Molecular Biology Laboratory) in the National Institute of Hygiene in Morocco presented the strategy of diagnosis adopted in Morocco and the techniques used: ELISA testing for HIV screening, Western Blot test for HIV confirmation, rapid HIV testing for NGOs to be confirmed by Western Blot, real-time PCR for HIV viral load titration. For TB diagnosis, microscopic examination and histopathology are used at provincial level; TB culture is used at central and regional level; susceptibility testing is reserved for the National Reference TB Laboratory.

\section{Conclusion and recommendations of the workshop}

Demographical data on migrant populations are to be completed especially for undocumented migrants in the southern countries of the Mediterranean region. In some countries, epidemiological data and risk data analysis for HIV and TB in migrants are missing and need to be documented. Although NGOs are very active, the access for migrants to healthcare for migrants still need the support of health authorities and international organisations support. All speakers concluded by recommending that carrying out field studies will help to set up health programmes targeted at migrants.

References

1. Negro Calduch E, Diaz A, Diez M, for the project "Impact of migration on HIV and TB Epidemiology in the Mediterranean Area". Ethical and legal issues related to health access for migrant populations in the Euro-Mediterranean Area. Euro Surveill. 2008;13(50):pii=19061. Available from: http://www. eurosurveillance.org/ViewArticle.aspx?ArticleId=19061

2. Department of Economic and Social Affairs. Statistics Division. Recommendations on statistics of international migration. New York: United Nations; 1998. Statistical Papers Series M, No. 58, Rev. 1. Available from: http:// unstats.un.org/unsd/publication/SeriesM/SeriesM_58rev1E.pdf

3. National registry of AIDS cases. Madrid: Instituto de Salud Carlos III. Available from: http://www.isciii.es/htdocs/centros/epidemiologia/epi_sida. jsp 
4. Direction de l'epidemiologie et de lutte contre les maladies. [Homepage on the internet]. [Directorate of Epidemiology and fight against diseases]. Morocco: Ministere de la Sante. Available from: http://www.sante.gov.ma/ Departements/DELM/index-delm.htm

5. EuroHIV. HIV/AIDS Surveillance in Europe. Mid-year report 2007. Saint-Maurice: Institut de Veille Sanitaire, 2007. Report No. 76. Available from: http://www. eurohiv.org/reports/report_76/pdf/report_eurohiv_76.pdf

6. EuroHIV. HIV/AIDS Surveillance in Europe. Mid-year report 2006. Saint-Maurice: Institut de Veille Sanitaire, 2007. Report No. 74. Available from: http://www. eurohiv.org/reports/report_74/pdf/report_eurohiv_74.pdf

7. Estudio anónimo y no relacionado sobre la prevalencia de anticuerpos antiVIH 1 y 2 en recién nacidos de 8 comunidades autónomas. Años $1996-2005$. [Anonymous and independent study on the prevalence of antibodies to HIV 1 and 2 in infants of 8 regions. Years 1996-2005]. Madrid: Instituto de Salud Carlos III; 2006 November. [In Spanish]. Available from: http://www.isciii. es/htdocs/pdf/anr_nacidos1996_05.pdf

8. Informe sobre de casos de sida y prevalencia de VIH en IIPP. Año 20052006. [Report on AIDS cases and HIV prevalence in penitentiary institutions. Year 2005-2006]. Madrid: Ministerio del Interior, Dirección General de Instituciones Penitenciarias; 2007. [In Spanish].

9. The Joint United Nations Programme on HIV/AIDS. Mise en oeuvre de la declaration de l'engagement sur le VIH/SIDA; Rapport national 2008. 2008 Jan 30. Available from: http://data.unaids.org/pub/Report/2008/Morocco_2008_ country_progress_report_fr.pdf

10. HIV Centre for Clinical and Behavioural Studies. [Homepage on the internet] New York: New York State Psychiatric Institute, Columbia University. Available from: www.hivcenternyc.org

This article was published on 16 April 2009.

Citation style for this article: El Aouad R, Diez M, Cherkaoui I. Impact of immigration on HIV and tuberculosis epidemiology in the Euro-Mediterranean area. Euro Surveill. 2009;14(15):pij=19173. Available online: http://www.eurosurveillance.org/ViewArticle. 2009;14(15):pii=19173. 